\title{
BMJ Open Examining patient distress and unmet need for support across UK renal units with varying models of psychosocial care delivery: a cross-sectional survey study
}

Maaike Seekles (D), Paula Ormandy, Daiga Kamerāde

To cite: Seekles M, Ormandy P, Kamerāde D. Examining patient distress and unmet need for support across UK renal units with varying models of psychosocial care delivery: a cross-sectional survey study. BMJ Open 2020;10:e036931. doi:10.1136/ bmjopen-2020-036931

- Prepublication history for this paper is available online. To view these files, please visit the journal online (http://dx.doi. org/10.1136/bmjopen-2020036931).

Received 10 January 2020 Revised 11 June 2020 Accepted 20 July 2020

Check for updates

(C) Author(s) (or their employer(s)) 2020. Re-use permitted under CC BY-NC. No commercial re-use. See rights and permissions. Published by BMJ.

School of Health and Society, University of Salford, Salford, UK

Correspondence to

Maaike Seekles;

m.I.seekles1@salford.ac.uk

\section{ABSTRACT}

Objective To examine in-centre haemodialysis patients' emotional distress and need for support across UK renal units with varying models of psychosocial service provision.

Design The study used a cross-sectional survey design. Logistic regression analysis was used to examine patient distress, as captured by the Distress Thermometer, and need for support, across different renal units.

Setting Seven renal units across England, Wales and Scotland. The units were purposively selected so that varying workforce models of renal psychosocial services were represented.

Participants In total, 752 patients were on dialysis in the participating centres on the days of data collection. All adult patients, who could understand English, and with capacity (as determined by the nurse in charge), were eligible to participate in the study. The questionnaire was completed by 509 patients, resulting in an overall response rate of $67.7 \%$.

Outcome measures The prevalence of distress and patient-reported need for support.

Results The results showed that $48.9 \%$ ( $95 \% \mathrm{Cl} 44.5$ to 53.4) of respondents experienced distress. A significant association between distress and models of renal psychosocial service provision was found $\left(\chi^{2}(6)=15.05\right.$, $p=0.019)$. Multivariable logistic regression showed that patients in units with higher total psychosocial staffing ratios (OR 0.65 (95\% $\mathrm{Cl} 0.47$ to 0.89 ); $\mathrm{p}=0.008$ ) and specifically higher social work ratios (OR $0.49(95 \% \mathrm{Cl}$ 0.33 to 0.74$) ; p=0.001$ ) were less likely to experience distress, even after controlling for demographic variables. In addition, a higher patient-reported unmet need for support was found in units where psychosocial staffing numbers are low or non-existent $\left(\chi^{2}(6)=37.80\right.$, $\mathrm{p}<0.001)$.

Conclusions The novel findings emphasise a need for increased incorporation of dedicated renal psychosocial staff into the renal care pathway. Importantly, these members of staff should be able to offer support for psychological as well as practical and social care-related issues.
Strengths and limitations of this study

- This is the first study to investigate distress in renal patients across varying models of psychosocial service delivery, providing a unique health systems research perspective.

- The sample size of the study was large, with participants from seven renal units across the UK.

- The overall response rate was high, increasing the probability that the findings are representative of the patients in participating units.

- Those from black and minority ethnic groups were under-represented in the responses.

- The cross-sectional study design provided a snapshot of distress in renal patients, but future studies should consider a longitudinal panel study to capture changes in distress over time, for individuals and groups of patients along the renal pathway.

\section{INTRODUCTION}

Chronic kidney disease (CKD) is a worldwide public health problem, with increasing incidence and prevalence, high costs and poor outcomes. ${ }^{1}$ The disease is typically progressive and can be divided into five stages of increasing severity, with treatments based on these stages. For a small, but significant percentage of people, CKD progresses to end-stage renal disease (ESRD). At this stage, which is irreversible, the kidneys are no longer able to function and renal replacement therapy (RRT) - dialysis or transplantation-becomes necessary to maintain life. ${ }^{23}$ According to the latest Renal Registry data, there were 64887 patients receiving RRT in the UK at the end of 2017. Of these, $37.3 \%$ received in-centre haemodialysis (ICHD), $5.4 \%$ received peritoneal dialysis, $2.0 \%$ dialysed at home and $55.2 \%$ had received a transplant. ${ }^{4}$ People with CKD often have a range of comorbid disorders. Some of these, 
such as hypertension and diabetes, are risk factors of the disease. Others, such as heart failure or chronic pulmonary disease, are often coprevalent as a result of CKD or because of shared risk factors. ${ }^{5}{ }^{6}$ Living with CKD, and especially ESRD, provides many ongoing physical, emotional, financial and/or social challenges throughout a patient's renal journey. These consequences of the disease and its comorbidities make patient access to expertise in medical, nursing, dietetic, pharmacological, psychological and social care areas essential. ${ }^{7}$

In recent years, against a global backdrop of shortages in the nephrology workforce, there have been increasing calls for a change in the existing models of renal care to manage the demands of an increasing CKD burden. A collaborative care model, in which a greater share of the work is performed by allied health professionals (including psychosocial staff), is one of the proposed solutions. ${ }^{8}$ Acceptance that a focus on the psychosocial needs of the patients should be included in comprehensive psychosocial care has grown in recent years, ${ }^{9}$ yet this has not always translated into practice. Internationally, limited evidence suggests differences in the level and type of renal psychosocial care accessible to patients. A recent Europe-wide study found that multidisciplinary teams (defined as teams consisting of allied health professionals, eg, expert nurses, dieticians and social workers) were routinely available to patients with CKD in only eight out of 17 studied countries. ${ }^{10}$ In the USA and Australia, renal dedicated social workers appear to be the point person responsible for providing psychosocial care, although in both countries high case loads and exceeded benchmarks were reported. ${ }^{11-13}$ US renal social workers are in a special position, since ESRD is the only disease for which Medicare's Conditions for Coverage Mandate requires a masters-level trained social worker on every interdisciplinary team. ${ }^{14}$ Generally, in the UK, while all members of staff within the renal unit have a role in providing general psychosocial support, the core specialist psychosocial professionals include a psychologist (clinical, counselling or health), a counsellor or a psychotherapist, and/or a social worker. There are differences in the training and expertise of these professionals. A psychologist will have undertaken a minimum of 6 years of training to doctorate level and will mainly support patients with diagnosed, complex mental health issues; a counsellor or psychotherapist will have a minimum of an undergraduate diploma, but may have a bachelor's degree or postgraduate qualifications and will support patients with emotional or behavioural issues; a renal social worker will have a bachelor's degree in social work and/or a postgraduate social work qualification and, broadly speaking, focuses on improving patients' quality of life and functioning in society by connecting them to community and social care services. While the lines between these professions often seem blurred, it is important to recognise that these roles are not interchangeable and each professional uses different, and sometimes complementary, approaches to support patients. A recent workforce report by Seekles et $a l^{15}$ showed that in the UK, over the past 15 years, a change in renal psychosocial staffing levels had taken place. The number of renal social workers had reduced dramatically, while renal psychologists and counsellors had grown in numbers. In the UK too, recommended staff-to-patient ratios were far from being met. A general UK renal psychosocial service provision model was lacking: most renal units incorporated different psychosocial teams, made up of varying types and numbers of staff, while some units completely lacked any form of dedicated psychosocial support. ${ }^{16}$

Currently, UK guidelines from the National Health Service England ${ }^{17}$ and the National Institute for Health and Care Excellence ${ }^{3}$ vaguely state that haemodialysis (HD) patients 'must have access to' psychosocial services, without clarifying the type and number of staff that should be accessible. This, and the large variety in models of service provision found, reflects a lack of empirical studies on the delivery of psychosocial services that can inform evidence-based staffing standards and regulations. This paper presents the findings of an investigation that used the concept of distress-broadly defined as 'a multifactorial unpleasant experience of a psychological (ie, cognitive, behavioural, emotional), social, spiritual, and/ or physical nature ${ }^{, 18}$ - to explore the association between ICHD patient's distress, their perceived need for support and UK models of renal psychosocial service delivery. Studies have found that distress can have a negative effect on quality of life, health outcomes and costs, emphasising the importance of addressing psychosocial issues in renal patients. ${ }^{19-21}$ The research question asked whether there is a relationship between different UK models of renal psychosocial service delivery, self-reported distress and need for support of ICHD patients. This investigation forms part of a larger, nationwide mixed methods study that aims to understand how renal psychosocial services are delivered in the UK.

\section{METHODS}

\section{Participating renal units}

The study used a cross-sectional survey design and included ICHD patients from seven main renal units across England $(n=3)$, Wales $(n=2)$ and Scotland $(n=2)$. The sites were purposively selected out of a total of 89 renal units, informed by the outcomes of a recent renal psychosocial workforce mapping, ${ }^{15}$ to ensure an inclusion of different staffing ratios and models of psychosocial service provision. Ratios were determined based on the number of RRT patients (as opposed to ICHD patients) from the latest UK Renal Registry, ${ }^{4}$ since the members of psychosocial staff cover the whole range of RRT patients, including transplant patients. To obtain a numerical value for ratios suitable for comparisons and analysis, the fulltime equivalent (FTE) of psychosocial staff was divided by the number of RRT patients in that unit, multiplied by 100. For example, one FTE social work per 100 patients would equate to a ratio of 1 . Throughout this paper, the 
Table 1 Characteristics of participating renal units

\begin{tabular}{lccll}
\hline Unit name & ICHD patients $(\mathbf{n})$ & RRT patients $(\mathbf{n})$ & Satellite units $(\mathbf{n})$ & Psychosocial staffing model \\
\hline Unit A & $0-250$ & $501-750$ & $6-8$ & No dedicated staff \\
Unit B & $251-500$ & $1001-1250$ & $3-5$ & Psychology \\
Unit C & $251-500$ & $1001-1250$ & $3-5$ & Counselling and welfare advice \\
Unit D & $251-500$ & $751-1000$ & $3-5$ & $\begin{array}{l}\text { Psychology, counselling and social } \\
\text { work }\end{array}$ \\
Unit E & $251-500$ & $751-1000$ & $3-5$ & Social work and psychiatry \\
Unit F & $0-250$ & $251-500$ & $0-2$ & Psychology and social work \\
Unit G & $0-250$ & $0-250$ & $0-2$ & Psychology and social work \\
\hline
\end{tabular}

ICHD, in-centre haemodialysis; RRT, renal replacement therapy.

units have been sorted based on their patient ratios, with unit A having no renal dedicated psychosocial staff available and unit G having the highest ratio of total psychosocial staff available to its patients. To protect the anonymity of the participating renal units, exact characteristics that could lead to identification cannot be provided. Instead, table 1 provides an overview of indicators of unit size, in addition to the psychosocial provision model. As can be seen, all units have different models of psychosocial service provision, apart from units $\mathrm{F}$ and $\mathrm{G}$, who differ in their staff-to-patient ratios.

On average, ratios of renal dedicated psychosocial staffing in the study sites are better than ratios found across the UK. The average ratio of psychologists in this study is 1 FTE per 562patients, compared with an average of 1 FTE per 1392 patients. For social workers, the average ratio in this study is 1 FTE per 344 patients, compared with 1 FTE per 614 patients across the UK. ${ }^{15}$ Comparison of overall staffing ratios was not possible due to a lack of comparable data. Furthermore, only units B and D had a black and minority ethnic population of a similar size as the overall UK dialysis population, while the other units served predominantly or completely white populations.

\section{Patient and public involvement}

The study design was developed with input from patient representatives, who were asked to comment on the appropriateness of the outcome measures and provide insight into the expected burden and time required for participation. Patients were not involved in the recruitment or further conduct of the study. The results will be disseminated to participants and the wider renal units through Kidney Care UK's marketing channels (website, posters) at the end of the project.

\section{Participants and recruitment}

All adult ICHD patients who could understand English, and with capacity (as determined by the nurse in charge), were eligible to participate in the study. Data collection took place between March 2018 and July 2019. Renal unit staff at each Trust provided all eligible patients with a letter of invitation and an information sheet. The University research team would visit the unit 1 week later to distribute the questionnaires (with information sheets), which were to be completed by patients while on dialysis. Consent was assumed on return of the completed questionnaire. To prevent selection bias, patients were allowed help with completion of the questionnaire.

\section{Sample}

The sample size was restricted by the number of patients dialysing in the renal units. In total, 752 patients were on dialysis in the participating centres on the days of data collection. Of these, 509 completed the questionnaire, resulting in an overall response rate of $67.7 \%$. Nonparticipants either refused to participate, were asleep, did not feel well enough to participate, did not speak English or lacked capacity. The response rates in participating units varied from $49.0 \%$ in unit $\mathrm{F}$ to around $82.0 \%$ in units D and G.

As can be seen in table 2 the majority of respondents were male and aged over 70 years old. This distribution of gender is similar to the general UK ICHD population, which is reported to consist of $61.9 \%$ of males. The median age of the general ICHD population is 67.5 years. ${ }^{4}$ The study sample was almost entirely made up of people from the white ethnic group, which is different from the total ICHD population, in which this group makes up around $70 \%$ of patients. ${ }^{4}$ Furthermore, the majority of patients had been on dialysis for 6 months to 3 years, lived together with their partner or family and were retired.

Four respondents did not complete the Distress Thermometer (DT), while others did not provide information on other questions, leading to varying numbers of missing data. Instead of using listwise deletion, which would have resulted in the loss of important information on some analyses, pairwise deletion was used to maximise the available data on an analysis by analysis basis.

\section{Measurements}

The questionnaire used the US National Comprehensive Cancer Network's ${ }^{\mathrm{i}}$ DT and Problems Checklist ${ }^{18}$ as the

${ }^{\mathrm{i}}$ The DT was referenced with permission from the NCCN Guidelines ${ }^{\circledR}$ for Distress Management V.3.2019 () National Comprehensive Cancer Network, Inc. 2019. All rights reserved. 
Table 2 Respondent characteristics and proportion per subgroup

\begin{tabular}{lll}
\hline Characteristic & n & $\%$ \\
\hline Total & 509 & 100
\end{tabular}

Main unit (psychosocial model)

$\begin{array}{lcr}\text { Unit A (no staff) } & 64 & 12.6 \\ \text { Unit B (psychology) } & 65 & 12.8 \\ \text { Unit C (counselling+welfare advice) } & 98 & 19.3 \\ \text { Unit D (social } & 73 & 14.3 \\ \text { work+psychology+counselling) } & & \\ \text { Unit E (social work+psychiatry) } & 104 & 20.4 \\ \text { Unit F (social work+psychology) } & 47 & 9.3 \\ \text { Unit G (social work+psychology) } & 58 & 11.4\end{array}$

Sex

\begin{tabular}{|c|c|c|}
\hline Male & 311 & 61.1 \\
\hline Female & 192 & 37.7 \\
\hline Missing & 6 & 1.2 \\
\hline \multicolumn{3}{|l|}{ Age category } \\
\hline 18-39 & 50 & 9.8 \\
\hline $40-49$ & 51 & 10.0 \\
\hline $50-59$ & 97 & 19.1 \\
\hline $60-69$ & 104 & 20.4 \\
\hline$\geq 70$ & 201 & 39.5 \\
\hline Missing & 6 & 1.2 \\
\hline \multicolumn{3}{|l|}{ Ethnicity } \\
\hline White & 460 & 90.4 \\
\hline Other & 42 & 8.3 \\
\hline Missing & 7 & 1.4 \\
\hline \multicolumn{3}{|l|}{ Time on dialysis } \\
\hline$<6$ months & 87 & 17.1 \\
\hline 6 months to 3 years & 193 & 37.9 \\
\hline $3-5$ years & 91 & 17.9 \\
\hline$>5$ years & 130 & 25.5 \\
\hline Missing & 8 & 1.6 \\
\hline \multicolumn{3}{|l|}{ Living situation } \\
\hline Living alone & 147 & 29.7 \\
\hline Living together & 349 & 70.3 \\
\hline Missing & 13 & 2.6 \\
\hline \multicolumn{3}{|l|}{ Employment situation } \\
\hline Employed & 67 & 13.2 \\
\hline Unemployed & 14 & 2.8 \\
\hline Unable to work & 183 & 36.0 \\
\hline Retired & 237 & 46.6 \\
\hline Missing & 8 & 1.6 \\
\hline
\end{tabular}

Accessed December fourth, 2019. Available online at www. NCCN.org. NCCN makes no warranties of any kind whatsoever regarding their content, use or application and disclaims any responsibility for their application or use in any way. instrument to measure distress. Although initially developed to screen for distress in oncology patients, the DT has been validated for use in the UK renal population. ${ }^{22}$ It is a simple one-item screening tool, designed to be part of health professionals' daily practice, which asks patients to rate their distress on a 11-point Likert scale from 0 (nothing) to 10 (extreme). For analysis, distress was examined through a binary variable of distress 'caseness', with DT scores of $\geq 4$ denoting distress. ${ }^{18}$ Studies using the DT in renal care are limited, but a meta-analysis of studies in oncology patients found a good balance between pooled sensitivity (0.81, 95\% CI 0.79 to 0.82$)$ and pooled specificity $(0.72,95 \%$ CI 0.71 to 0.72$)$ at the cut-off score of 4 when comparing the DT to other diagnostic tools, such as the Hospital Anxiety and Depression Scale and Beck's Depression Inventory. ${ }^{23}$ However, for the current study, this is less relevant since the DT was not used to identify patients with diagnosable mood disorders, but to determine the prevalence of distress defined as 'an unpleasant emotional state' and allow for comparisons across units. Distress, here, does not unambiguously refer to the same concept. ${ }^{24}$

Patients indicated which issues were causing them distress by ticking a box on the Problem Checklist. The questionnaire included further tick-box questions, with the options yes or no, to determine whether patients were currently in receipt of psychosocial support; and if not, whether they would like to receive this support. Information on sociodemographic characteristics (sex, age, ethnicity, living situation and employment situation) was captured using closed questions.

\section{Data analysis methods}

The prevalence of distress and $95 \%$ CIs were calculated using the cut-off score described in the Measurements section. Univariate logistic regression was then applied to examine the associations between distress, study sites and demographic characteristics. Subsequently, multivariable logistic regression was used to identify whether study site, staffing ratios and further demographic variables served as predictors of distress. All variables were entered simultaneously. Finally, univariate logistic regression was used to investigate the perceived need for support and prevalence of problem types across the study sites. All analyses were conducted using Stata V.14.2 statistical software. ${ }^{25}$

\section{RESULTS}

Overall, a distress score of $\geq 4$ was observed in 247 out of 505 respondents, indicating that $48.9 \%$ (95\% CI 44.5 to 53.4) of ICHD patients were experiencing some form of distress. Mild to moderate distress (DT score 4-6) was identified in $25.7 \%$ of patients ( 130 cases, $95 \%$ CI 22.0 to 29.8 ). A DT score of $\geq 7$ was observed for 117 cases, indicating that $23.2 \%$ of patients (95\% CI 19.6 to 27.1 ) across all study sites were experiencing severe distress.

Findings from univariate analyses (table 3) showed an association between distress and study site, with patients 
Table 3 Summary of univariate logistic analyses for association between distress and demographic variables

\begin{tabular}{|c|c|c|c|c|}
\hline Variable & $\begin{array}{l}\text { Distress (DT } \geq 4) \\
\%(n)\end{array}$ & $\begin{array}{l}\text { OR } \\
(95 \% \mathrm{Cl}) \\
\end{array}$ & $P$ value & $\operatorname{LR} \chi^{2}$ \\
\hline Total $(n=505)$ & $48.9(247)$ & & & \\
\hline Main unit $(\mathrm{n}=505)$ & & & & $\chi^{2}(6)=15.05, p=0.019$ \\
\hline A & $56.3(36)$ & & - & \\
\hline B & $56.3(36)$ & 1.00 (0.50 to 2.01$)$ & 1.00 & \\
\hline C & $59.2(58)$ & $1.13(0.60$ to 2.14$)$ & 0.712 & \\
\hline D & $48.0(35)$ & 0.72 (0.37 to 1.41$)$ & 0.332 & \\
\hline E & $43.3(45)$ & 0.59 (0.32 to 1.11$)$ & 0.103 & \\
\hline $\mathrm{F}$ & $34.1(15)$ & $0.40(0.18$ to 0.89$)$ & 0.025 & \\
\hline G & $37.9(22)$ & $0.48(0.23$ to 0.98$)$ & 0.044 & \\
\hline Sex $(n=499)$ & & & & $\chi^{2}(1)=2.23, p=0.135$ \\
\hline Male & $46.3(143)$ & & & \\
\hline Female & $53.2(101)$ & 1.32 (0.92 to 1.89$)$ & 0.136 & \\
\hline Age category $(n=499)$ & & & & $\chi^{2}(4)=22.36, p<0.001$ \\
\hline 18-39 & $60.0(30)$ & 2.46 (1.30 to 4.64$)$ & 0.005 & \\
\hline $40-49$ & $62.0(31)$ & 2.68 (1.41 to 5.07$)$ & 0.003 & \\
\hline $50-59$ & $61.9(60)$ & 2.66 (1.61 to 4.39$)$ & $<0.001$ & \\
\hline $60-69$ & $47.1(49)$ & 1.46 (0.90 to 2.36$)$ & 0.122 & \\
\hline$\geq 70$ & $37.9(75)$ & & - & \\
\hline Ethnicity $(n=498)$ & & & & $\chi^{2}(1)=1.22, p=0.269$ \\
\hline White & $48.3(220)$ & & - & \\
\hline Other & $57.1(24)$ & $1.43(0.76$ to 2.71$)$ & 0.272 & \\
\hline Time on dialysis $(n=497)$ & & & & $\chi^{2}(3)=2.99, p=0.393$ \\
\hline$<6$ months & $48.8(42)$ & 1.28 (0.74 to 2.22$)$ & 0.371 & \\
\hline 6 months to 3 years & $52.1(100)$ & 1.46 (0.93 to 2.30$)$ & 0.097 & \\
\hline $3-5$ years & $51.1(46)$ & 1.40 (0.82 to 2.42$)$ & 0.216 & \\
\hline$>5$ years & $42.6(55)$ & & - & \\
\hline Living situation $(\mathrm{n}=492)$ & & & & $\chi^{2}(1)=1.00, p=0.316$ \\
\hline Living alone & $52.1(76)$ & & - & \\
\hline Living together & $47.1(163)$ & 0.82 (0.56 to 1.21$)$ & 0.316 & \\
\hline Employment situation ( $\mathrm{n}=497$ ) & & & & $\chi^{2}(3)=26.17, p<0.001$ \\
\hline Employed & $42.4(28)$ & 1.14 (0.65 to 1.98$)$ & 0.649 & \\
\hline Unemployed & $78.6(11)$ & 5.65 (1.54 to 20.83$)$ & 0.009 & \\
\hline Unable to work & $61.2(112)$ & 2.43 (1.64 to 3.62$)$ & $<0.001$ & \\
\hline Retired & $39.3(92)$ & & - & \\
\hline
\end{tabular}

DT, Distress Thermometer; LR, likelihood ratio.

in units $\mathrm{F}$ and $\mathrm{G}$ less likely to be cases than in units $\mathrm{A}, \mathrm{B}$ and $\mathrm{C}$. Further associations were found with age group and employment situation. Specifically, those aged 18-39, 40-49 and 50-59 and those patients who were unemployed or considered themselves unable to work were significantly more likely to be distressed than those aged 70 or above and retired.

A multivariable logistic regression model (table 4) including renal unit and other demographic variables sex, age, ethnicity, time on dialysis, living situation and employment situation was found to be a significant predictor of distress (Likelihood Ratio (LR) $\chi^{2}(19)=56.77$, $\mathrm{p}<0.001)$. The renal unit that patients belonged to significantly predicted distress, with being a patient in unit $\mathrm{E}(\beta$ $-0.718)$ or $F(\beta-1.083)$ significantly reducing the likelihood of distress compared with being a patient in unit A. Time on dialysis was also found to be a predictor of distress, with being on dialysis for a period of 3-5 years significantly increasing the likelihood of distress. Age group and employment situation were not found to be predictors. 
Table 4 Multivariable regression model for predictors of distress including renal unit and demographic variables

\begin{tabular}{lccc} 
Predictor & B (SE) & OR (95\% Cl) & P value \\
\hline Constant & $0.176(0.348)$ & &
\end{tabular}

Renal unit

\begin{tabular}{|c|c|c|c|}
\hline \multicolumn{4}{|l|}{ A (reference) } \\
\hline B & $-0.161(0.387)$ & 0.851 (0.40 to 1.82$)$ & 0.676 \\
\hline C & $0.176(0.348)$ & 1.193 (0.60 to 2.36$)$ & 0.612 \\
\hline D & $-0.411(0.375)$ & 0.663 (0.32 to 1.38$)$ & 0.272 \\
\hline E & $-0.718(0.351)$ & 0.488 (0.25 to 0.97$)$ & 0.041 \\
\hline $\mathrm{F}$ & $-1.083(0.461)$ & $0.338(0.14$ to 0.84$)$ & 0.019 \\
\hline G & $-0.678(0.395)$ & 0.508 (0.23 to 1.10$)$ & 0.086 \\
\hline \multicolumn{4}{|l|}{ Sex } \\
\hline \multicolumn{4}{|l|}{ Male (reference) } \\
\hline Female & $0.237(0.202)$ & 1.268 (0.85 to 1.89$)$ & 0.241 \\
\hline \multicolumn{4}{|l|}{ Age category } \\
\hline $18-39$ & $0.782(0.444)$ & 2.186 (0.92 to 5.22$)$ & 0.078 \\
\hline $40-49$ & $0.776(0.439)$ & 2.173 (0.92 to 5.13 ) & 0.077 \\
\hline $50-59$ & $0.593(0.369)$ & 1.809 (0.89 to 3.73$)$ & 0.108 \\
\hline $60-69$ & $0.164(0.282)$ & 1.179 (0.68 to 2.05$)$ & 0.560 \\
\hline \multicolumn{4}{|l|}{$\geq 70$ (reference) } \\
\hline \multicolumn{4}{|l|}{ Ethnicity } \\
\hline \multicolumn{4}{|l|}{ White (reference) } \\
\hline Other & $0.0366(0.388)$ & 1.037 (0.48 to 2.22) & 0.925 \\
\hline \multicolumn{4}{|l|}{ Time on dialysis } \\
\hline$<6$ months & $0.411(0.309)$ & 1.509 (0.82 to 2.77$)$ & 0.183 \\
\hline 6 months to 3 years & $0.360(0.249)$ & 1.434 (0.88 to 2.34$)$ & 0.149 \\
\hline $3-5$ years & $0.606(0.305)$ & 1.833 (1.01 to 3.34$)$ & 0.047 \\
\hline \multicolumn{4}{|l|}{$>5$ years (reference) } \\
\hline \multicolumn{4}{|l|}{ Living situation } \\
\hline \multicolumn{4}{|l|}{ Living alone (reference) } \\
\hline Living together & $-0.321(0.215)$ & 0.725 (0.48 to 1.10$)$ & 0.134 \\
\hline \multicolumn{4}{|l|}{ Employment situation } \\
\hline Employed/in education & $-0.511(0.394)$ & 0.560 (0.28 to 1.30$)$ & 0.194 \\
\hline Unemployed & $1.401(0.769)$ & 4.058 (0.90 to 18.33$)$ & 0.069 \\
\hline Unable to work & $0.583(0.311)$ & 1.791 (0.97 to 3.30$)$ & 0.061 \\
\hline \multicolumn{4}{|l|}{ Retired (reference) } \\
\hline $\mathrm{n}$ & 488 & & \\
\hline
\end{tabular}

Further regression analysis was undertaken to provide more insight into the relationship between distress and psychosocial staffing ratios. Three similar multivariable logistic regression models were created, differing only by inclusion of either the total ratio of renal dedicated psychosocial staff, the ratio of renal social workers or the ratio of renal psychologists/counsellors (table 5). The difference between psychologists and counsellors should be acknowledged and emphasised, yet it was decided to group these professions together in model 3 so that counselling staff (only present in two units) could be taken into account. In the units that had renal social work available, ratios varied from 0.19 to 0.53 . The variation in ratios for psychologists/counsellors was less; the ratios varied from 0.314 to 0.32 . All models included the demographics sex, ethnicity, age, living situation, time on dialysis and employment situation as predictors.

The results were as follows:

- Model 1 (including total ratios of psychosocial staff): a collective significant effect was found, LR $\chi^{2}(14)=47.68, p<0.001$. Specifically, the ratio of total psychosocial staff was found to significantly predict 
Table 5 Multivariable logistic regression models for predictors of distress including staff ratios and demographic variables

\begin{tabular}{|c|c|c|c|c|c|c|c|c|c|}
\hline \multirow[b]{2}{*}{ Predictor } & \multicolumn{3}{|l|}{ Model 1} & \multicolumn{3}{|l|}{ Model 2} & \multicolumn{3}{|l|}{ Model 3} \\
\hline & $\begin{array}{l}\text { B } \\
\text { (SE) }\end{array}$ & $\begin{array}{l}\text { OR } \\
(95 \% \mathrm{Cl})\end{array}$ & $P$ value & $\begin{array}{l}\text { B } \\
\text { (SE) }\end{array}$ & $\begin{array}{l}\text { OR } \\
\text { (95\% Cl) }\end{array}$ & $P$ value & $\begin{array}{l}B \\
\text { (SE) }\end{array}$ & $\begin{array}{l}\text { OR } \\
\text { (95\% Cl) }\end{array}$ & $P$ value \\
\hline Constant & $\begin{array}{l}-0.37 \\
(0.32)\end{array}$ & & & $-0.41(0.29)$ & & & $\begin{array}{l}-0.76 \\
(0.30)\end{array}$ & & \\
\hline \multicolumn{10}{|l|}{ Ratios } \\
\hline Total psychosocial staff & $\begin{array}{l}-1.11 \\
(0.43)\end{array}$ & $\begin{array}{l}0.33 \text { (0.14to } \\
0.77)\end{array}$ & 0.010 & & & & & & \\
\hline Psychology/counselling & & & & & & & $\begin{array}{l}-0.30 \\
(0.86)\end{array}$ & $\begin{array}{l}0.741 \text { ( } 0.14 \text { to } \\
4.02)\end{array}$ & 0.728 \\
\hline \multicolumn{10}{|l|}{ Sex } \\
\hline \multicolumn{10}{|l|}{ Male (reference) } \\
\hline $40-49$ & $\begin{array}{l}0.747 \\
(0.43)\end{array}$ & $\begin{array}{l}2.11 \text { ( } 0.91 \text { to } \\
4.92)\end{array}$ & 0.084 & $\begin{array}{l}0.763 \\
(0.43)\end{array}$ & $\begin{array}{l}2.15 \text { (0.92 to } \\
5.02)\end{array}$ & 0.078 & $\begin{array}{l}0.796 \\
(0.43)\end{array}$ & $\begin{array}{l}2.22(0.95 \text { to } \\
5.15)\end{array}$ & 0.064 \\
\hline $50-59$ & $\begin{array}{l}0.600 \\
(0.36)\end{array}$ & $\begin{array}{l}1.83(0.90 \text { to } \\
3.72)\end{array}$ & 0.096 & $\begin{array}{l}0.588 \\
(0.36)\end{array}$ & $\begin{array}{l}1.801 \text { ( } 0.88 \text { to } \\
3.67 \text { ) }\end{array}$ & 0.105 & $\begin{array}{l}0.665 \\
(0.36)\end{array}$ & $\begin{array}{l}1.946 \text { ( } 0.96 \text { to } \\
3.95)\end{array}$ & 0.065 \\
\hline $60-69$ & $\begin{array}{l}0.186 \\
(0.28)\end{array}$ & $\begin{array}{l}1.20 \text { ( } 0.70 \text { to } \\
2.08)\end{array}$ & 0.504 & $\begin{array}{l}0.191 \\
(0.28)\end{array}$ & $\begin{array}{l}1.210 \text { ( } 0.70 \text { to } \\
2.09)\end{array}$ & 0.494 & $\begin{array}{l}0.202 \\
(0.28)\end{array}$ & $\begin{array}{l}1.224 \text { ( } 0.71 \text { to } \\
2.10)\end{array}$ & 0.464 \\
\hline \multicolumn{10}{|l|}{$\geq 70$ (reference) } \\
\hline \multicolumn{10}{|l|}{ Ethnicity } \\
\hline \multicolumn{10}{|l|}{ White (reference) } \\
\hline $3-5$ years & $\begin{array}{l}0.624 \\
(0.30)\end{array}$ & $\begin{array}{l}1.87 \text { (1.04 to } \\
3.37)\end{array}$ & 0.037 & $\begin{array}{l}0.618 \\
(0.30)\end{array}$ & $\begin{array}{l}1.86(1.02 \text { to } \\
3.35)\end{array}$ & 0.041 & $\begin{array}{l}0.648 \\
(0.30)\end{array}$ & $\begin{array}{l}1.91 \text { (1.09 to } \\
3.42)\end{array}$ & 0.029 \\
\hline \multicolumn{10}{|l|}{$>5$ years (reference) } \\
\hline \multicolumn{10}{|l|}{ Living situation } \\
\hline \multicolumn{10}{|l|}{ Alone (reference) } \\
\hline Together & $\begin{array}{l}-0.267 \\
(0.21)\end{array}$ & $\begin{array}{l}0.77(0.51 \text { to } \\
1.16)\end{array}$ & 0.206 & $\begin{array}{l}-0.291 \\
(0.21)\end{array}$ & $\begin{array}{l}0.75 \text { (0.49 to } \\
1.13)\end{array}$ & 0.167 & $\begin{array}{l}-0.258 \\
(0.21)\end{array}$ & $\begin{array}{l}0.77(0.51 \text { to } \\
1.16)\end{array}$ & 0.217 \\
\hline \multicolumn{10}{|l|}{ Employment } \\
\hline Employed & $\begin{array}{l}-0.506 \\
(0.39)\end{array}$ & $\begin{array}{l}0.61 \text { ( } 0.28 \text { to } \\
1.29 \text { ) }\end{array}$ & 0.190 & $\begin{array}{l}-0.509 \\
(0.39)\end{array}$ & $\begin{array}{l}0.61 \text { ( } 0.28 \text { to } \\
1.29)\end{array}$ & 0.190 & $\begin{array}{l}-0.450 \\
(0.39)\end{array}$ & $\begin{array}{l}0.64(0.30 \text { to } \\
1.36)\end{array}$ & 0.244 \\
\hline Unemployed & $\begin{array}{l}1.248 \\
(0.76)\end{array}$ & $\begin{array}{l}3.49(0.79 \text { to } \\
15.5)\end{array}$ & 0.100 & $\begin{array}{l}1.323 \\
(0.76)\end{array}$ & $\begin{array}{l}3.76 \text { ( } 0.84 \text { to } \\
16.8)\end{array}$ & 0.084 & $\begin{array}{l}1.227 \\
(0.76)\end{array}$ & $\begin{array}{l}3.41 \text { ( } 0.77 \text { to } \\
15.1)\end{array}$ & 0.106 \\
\hline Unable to work & $\begin{array}{l}0.520 \\
(0.30)\end{array}$ & $\begin{array}{l}1.68 \text { (0.93 to } \\
3.04)\end{array}$ & 0.088 & $\begin{array}{l}0.534 \\
(0.30)\end{array}$ & $\begin{array}{l}1.71 \text { ( } 0.94 \text { to } \\
3.10)\end{array}$ & 0.080 & $\begin{array}{l}0.492 \\
(0.30)\end{array}$ & $\begin{array}{l}1.64 \text { (0.90 to } \\
2.95)\end{array}$ & 0.104 \\
\hline \multicolumn{10}{|l|}{ Retired (reference) } \\
\hline $\mathrm{n}$ & 488 & & 488 & & & 488 & & & \\
\hline
\end{tabular}

distress, with higher ratios of staff leading to a lower likelihood of distress $(\beta-1.11, p=0.010)$. Being on dialysis for a period of 3-5 years was also found to significantly increase the likelihood of distress.
- Model 2 (including ratios of social work staff): this model also returned a significant result, predicting distress, $\mathrm{LR} \chi^{2}(14)=52.57, \mathrm{p}<0.001$. A significant association was found between social worker ratios and 
Table 6 Univariate logistic analysis of patients reporting a perceived unmet need for support per study site

\begin{tabular}{lclr}
\hline & $\begin{array}{l}\text { \% unmet } \\
\text { need for } \\
\text { support }(\mathbf{n})\end{array}$ & OR $(95 \%$ Cl) & P value \\
\hline $\begin{array}{l}\text { Total } \\
(\mathrm{n}=499)\end{array}$ & $17.6(88)$ & & \\
A & $35.5(22)$ & & \\
B & $35.4(23)$ & $0.996(0.48$ to 2.06$)$ & 0.991 \\
\hline C & $12.5(12)$ & $0.260(0.12$ to 0.58$)$ & 0.001 \\
D & $16.9(12)$ & $0.370(0.17$ to 0.83$)$ & 0.016 \\
E & $8.7(9)$ & $0.172(0.073$ to 0.41$)$ & $<0.001$ \\
\hline F & $13.9(6)$ & $0.295(0.11$ to 0.81$)$ & 0.017 \\
\hline G & $6.9(4)$ & $0.135(0.043$ to 0.42$)$ & 0.001 \\
\hline
\end{tabular}

distress, with likelihood of distress reducing as social worker ratios increased $(\beta-1.86, p=0.001)$. Again, time on dialysis (3-5 years) was found to significantly predict distress.

- Model 3 (including ratios of psychology/counselling staff): overall, the model significantly predicted distress, LR $\chi^{2}(14)=40.60, \mathrm{p}<0.001$, but the ratio of psychology/counselling staff was not found to be a significant predictor $(\beta-0.30, \mathrm{p}=0.728)$ In this model, only time on dialysis (3-5 years) was found to significantly predict distress. To note, a model including psychology ratios only showed similar, non-significant results.

One or more practical issues (such as problems related to finances or housing) were reported by $43.4 \%$ of patients; $60.9 \%$ reported one or more emotional issues (such as depression or fears). It was found that $17.6 \%$ of respondents wanted to receive psychosocial support for their problems, but were not currently receiving any. Univariate analysis indicated that there were differences across units $\left(\chi^{2}(6)=37.80, \mathrm{p}<0.001\right)$, with patients in units C, D, E, F and G significantly less likely to report an unmet need for support than patients in units A and B (table 6). Of the people who reported a need for support, $75.9 \%$ were classed as distressed.

\section{DISCUSSION}

\section{Main findings}

It was found that almost half $(48.9 \%, 95 \%$ CI $44.5 \%$ to $53.4 \%$ ) of all ICHD patients participating in this study experienced some form of distress, indicating the need for psychosocial support and services. In general, our results suggest that there is a significant relationship between the different UK models of renal psychosocial service delivery and ICHD patient distress. An association between distress and models of psychosocial service provision was found and the results indicated that psychosocial staff-to-patient ratios significantly predict distress in patients. Specifically, patients in units with higher total psychosocial staff ratios and higher social work ratios were less likely to experience distress, even after controlling for their sex, age, ethnicity, time on dialysis, living situation and employment status. Furthermore, differences across units were found in patients reported unmet need for support, with patients in units with both practical (as provided by a social worker/welfare advisor) and emotional support (from a psychologist/counsellor) available significantly less likely to want (additional) support.

\section{Strengths and limitations}

The key limitation of this study is its cross-sectional nature. A longitudinal panel study that would measure patient's distress levels before and after receiving certain psychosocial services (or no such services) would have had a higher internal validity; however, such study was not possible for practical reasons. Due to the selection of study sites based on psychosocial service provision models, the average psychosocial staffing ratios in this study were higher than the overall UK renal psychosocial staffing ratios. Based on our findings, this suggests that generalising these results to the whole ICHD population could underestimate overall distress prevalence. Importantly, one of the strengths of this study is the high response rate. Even the lowest response rate (in unit F) was still relatively high $(49 \%)$, although variability between the units was found. There is however no indication that response rate variability affected the results, with the highest (unit G) and lowest (unit F) response rates showing the lowest distress prevalence. Of relevance for the aim of exploring distress across different models of service provision, this increases the probability that the scores are representative of the patients in the participating units. To our knowledge, this is the first UK study to show an impact of renal social worker staffing levels on patient distress. This is not to say that renal psychologists and counsellors do not impact patient distress levels. The ratios of psychological staff were much more equal across units than the social work ratios, which could have contributed to the current findings. Further research could explore distress across units that have notable differences in psychology staffing levels. Due to a lack of available data, it was not possible to examine the current findings in the wider, unit-specific context, including factors such as patients' access and use of general psychosocial services in the hospital or community. However, in-depth qualitative research was completed with renal staff to explore the wider process of psychosocial service delivery in each study site in a linked component of this study (findings to be reported elsewhere).

\section{Implications}

This is the first study to explore distress in ICHD patients across different models of renal psychosocial service provision. While the overall prevalence of distress was in line with estimates from other studies that used self-reported measures for depression and anxiety, ${ }^{9}{ }^{20}$ it is the difference in prevalence across units that is of importance. 
Associations between distress and demographic variables have been widely reported in other studies, ${ }^{26}{ }^{27}$ however our results show that after accounting for models of service provision, other demographic factors (apart from time on dialysis) do not emerge as significant predictors of distress. This finding contradicts recently published findings by Damery et al who reported no influence of service delivery models on distress in their study. ${ }^{26}$ There are a couple of possible explanations for this discrepancy. First, Damery et al only compared the prevalence of mild to moderate distress, leaving the prevalence of severe distress out of their analysis and excluding patients using psychiatric services since CKD stage 5 from participation. In the context of psychosocial service delivery, the current study took all levels of distress into account and did not exclude those who were already receiving support. Second, while Damery et al did not report staffto-patient ratios, only renal psychologists are mentioned, which appears to reflect little variation in models of service provision across the participating units. Any differences in staffing levels might have been too small to result in differences in patient distress. Finally, there was no mention of the presence of renal social workers, whose availability plays an important role in reducing patient distress, according to the current findings.

The findings of this study are relevant for policymakers and practitioners in allocating resources to the management of distress in renal patients and in the wider context of psychosocial service delivery for those with long-term conditions. Not only does the evidence presented here show that renal psychosocial staff play a role in reducing patient distress, the results also highlight a higher patientreported need for these services in hospitals where psychosocial staffing numbers are low or non-existent. This is in line with Damery et al who found higher levels of need in units without renal psychologists available, compared with those with renal psychologists available. ${ }^{26}$ Yet, psychosocial services have steadily reduced over the last years, ${ }^{16}$ leaving patients having to look for support from services provided in the community. The results could indicate that these services are inaccessible or unable to provide the support patients need, leading to higher distress. Further research is needed to explore whether this is the case for the whole dialysis population, including patients on home HD and peritoneal dialysis.

Symptoms of distress can have a negative effect on patient quality of life, medical outcomes and costs, through reduced treatment adherence and increased rates of mortality, hospitalisation and length of hospital stay. ${ }^{19-21}$ Therefore, the findings emphasise a need for increased numbers of integrated psychosocial staff and a renal psychosocial care pathway, which, importantly, should include practical as well as emotional support. However, the main challenge to implementing psychosocial support is the lack of robust evidence to indicate adequate psychosocial staffing levels. While further investigation into appropriate staffing levels is necessary and the wider number of patients on all treatment modalities should be taken into account to determine these, the findings provide a first indication of the minimum ratios of psychosocial staff required. The first participating unit with a dedicated social worker to have significantly lower distress levels than a unit without any support had a staffing ratio of 1 social worker per 392 RRT patients; the staffing ratio in the first unit with a dedicated psychologist to have significantly lower distress levels was 1 psychologist per 525 RRTpatients. For social work, this is still much higher than recommended staffing ratios of 1 full-time worker per 140 RRTpatients, to allow access to both routine and complex social work support for each patient as they move along the renal pathway. A further challenge to the implementation of renal psychosocial services is ensuring that access to these services is equitable across the country, not just based on a postcode lottery. This study highlighted geographical differences in distress prevalence, related to access to renal dedicated psychosocial services. In addition, it is important to consider the role that dialysis staff play in the process of delivering psychosocial services. There is the expectation that dialysis staff support patients who experience lower level distress ${ }^{28}$ and psychosocial staff are often dependent on dialysis staff to inform, identify and refer patients in need for support to their service. Yet, a recent study by Combes $e t a l^{29}$ found that dialysis staff experience significant barriers in identifying and responding to distress, related to skills and knowledge, but also role perceptions.

To relieve some of the dependence on dialysis staff, screening patients for distress could be another way to identify patients in need. It is essential that the focus of this screening is not only on detecting clinically significant distress that could warrant a psychological intervention. Instead, for it to identify patients that could benefit from any type of psychosocial service, screening processes should bring patients to light who are experiencing distress, in the wider sense of the word, and/or psychosocial issues. For example, practical problems (such as issues with social care or transport) would not necessarily make a patient report distress that would meet the criteria for a formal diagnosis of anxiety or depression. Yet, in order to solve these problems and prevent them from contributing to negative health outcomes, a patient might still require support from a social worker. The use of the DT and Problem Checklist, already recommended in US oncology care guidelines, ${ }^{18}$ would allow for such a wide approach to screening and has been found to be an acceptable tool in the renal population. ${ }^{22}$ Still, even with this wide approach to capturing distress, our results show that it cannot be assumed that distress equals need for support. As such, any screening tool should always include a question that captures a patient-reported need and want for psychosocial services.

In conclusion, our findings support the incorporation of dedicated psychosocial support in the renal care pathway. At a time of calls for the evaluation and restructuring of CKD care models to improve outcomes and reduce the costs of care, the need for true integration of renal psychosocial services in new models of care can no longer be ignored. 
Twitter Maaike Seekles @maaikeseekles

Acknowledgements The authors would like to thank the staff and patients of the participating renal units for their assistance and participation.

Contributors MS and PO were involved in the design and data collection. MS and DK designed a data analysis plan and MS undertook the data analysis under supervision and support from DK. MS drafted the manuscript under supervision from PO and DK, who both completed revisions. All authors provided intellectual content of critical importance to the work described and have read and approved the final manuscript.

Funding This work is part of a larger Industrial Case PhD Studentship, cofunded by KCUK and the Higher Education Innovation Fund.

Disclaimer KCUK identified the focus of the study, but had no involvement in the data collection, analysis or writing of this manuscript.

Competing interests The authors report a grant from KCUK during the conduct of the study. PO also discloses personal fees from Baxter International and grants from KCUK, Kidney Research UK, National Institute of Health Research, and the British Renal Society, outside the submitted work.

Patient and public involvement Patients and/or the public were involved in the design, or conduct, or reporting, or dissemination plans of this research. Refer to the Methods section for further details.

Patient consent for publication Not required.

Ethics approval Ethical approval was obtained from the University of Salford Ethics Committee, the West of Scotland Research Ethics Service and Health Research Authority in October 2017 (Ref 17/WS/0185). In addition, all Research and Development offices from the participating Trusts approved the study and confirmed their capability and capacity to host the research.

Provenance and peer review Not commissioned; externally peer reviewed.

Data availability statement Data are available upon reasonable request. The data set used during the current study is available from the corresponding author on reasonable request after completion of the wider project.

Open access This is an open access article distributed in accordance with the Creative Commons Attribution Non Commercial (CC BY-NC 4.0) license, which permits others to distribute, remix, adapt, build upon this work non-commercially, and license their derivative works on different terms, provided the original work is properly cited, appropriate credit is given, any changes made indicated, and the use is non-commercial. See: http://creativecommons.org/licenses/by-nc/4.0/.

ORCID iD

Maaike Seekles http://orcid.org/0000-0002-7000-3624

\section{REFERENCES}

1 Jha V, Garcia-Garcia G, Iseki K, et al. Chronic kidney disease: global dimension and perspectives. Lancet 2013;382:260-72.

2 Jansen DL. Living with chronic kidney disease the role of illness perceptions treatment perceptions and social support. [PhD Thesis]. Utrecht University, 2012, [Accessed date 2 Feb 2018].

3 National Institute for Health and Care Excellence. Chronic kidney disease in adults. NICE, 2017. Available: https://www.nice.org.uk/ guidance/qs5 [Accessed 11 Dec 2017].

4 UK Renal Registry. UK Renal Registry 21st Annual Report - data to 31/12/2017. Bristol, UK, 2019. Available: https://www.renalreg.org/ publications-reports/

5 Bayliss EA, Bhardwaja B, Ross C, et al. Multidisciplinary team care may slow the rate of decline in renal function. Clin J Am Soc Nephrol 2011;6:704-10.

6 Tonelli M, Wiebe N, Guthrie B, et al. Comorbidity as a driver of adverse outcomes in people with chronic kidney disease. Kidney Int 2015;88:859-66.

7 Kidney Health Advisory Group. Kidney health: delivering excellence, 2013. Available: https://pkdcharity.org.uk/images/downloads/KidneyHealth-Delivering-Excellence.pdf [Accessed 11 Jun 2019].
8 Sharif MU, Elsayed ME, Stack AG. The global nephrology workforce: emerging threats and potential solutions! Clin Kidney J 2016:9:11-22.

9 Cukor D, Ver Halen N, Fruchter Y, et al. Psychosocial issues in chronic kidney disease patients. in: Kimmel PL, Rosenberg me, EDS. chronic renal disease. Academic Press 2015:229-36.

10 Bello AK, Levin A, Manns BJ, et al. Effective CKD care in European countries: challenges and opportunities for health policy. $\mathrm{Am} J$ Kidney Dis 2015;65:15-25.

11 Bale C, Douglas A, Jegatheesan D, et al. Psychosocial factors in end-stage kidney disease patients at a tertiary hospital in Australia. Int J Nephrol 2016;2016:1-6.

12 Campbell KL, Murray EM. Allied health services to nephrology: an audit of current workforce and meeting future challenges. J Ren Care 2013;39:52-61.

13 Merighi JR, Zheng M, Browne T. Nephrology Social Workers' Caseloads and Hourly Wages in 2014 and 2017: Findings from the National Kidney Foundation Council of Nephrology Social Workers Professional Practice Survey. Natl Kidney Found J Nephrol Soc Work 2018 http://education.kidney.org/JNSW-CE-Program (accessed 14 Nov 2019).

14 Browne T, Merighi JR, Washington T, et al. Nephrology Social Work. In: Handbook of Health Social Work. Wiley 2019:411-40.

15 Seekles ML, Coyne E, Ormandy P, et al. The UK renal psychosocial workforce : a mapping exercise, 2018. Available: http://usir.salford. ac.uk/46906/ [Accessed 10 Aug 2018].

16 Seekles ML, Ormandy P, Coyne E. Mapping the UK renal psychosocial workforce: the first comprehensive workforce survey. BMC Nephrol 2019;20:100.

17 NHS England. Service specifications: in centre haemodialysis (ICHD): main and satellite units, 2017. Available: https://www. england.nhs.uk/commissioning/wp-content/uploads/sites/12/ 2015/01/a06-serv-spec-haemodialysis-ichd.pdf [Accessed 11 Dec 2017].

18 Holland JC, Jacobsen PB, Riba MB. Distress management. in. Cancer Control 2001:88-93.

19 Palmer SC, Vecchio M, Craig JC, et al. Association between depression and death in people with CKD: a meta-analysis of cohort studies. Am J Kidney Dis 2013;62:493-505.

20 Schouten RW, Haverkamp GL, Loosman WL, et al. Anxiety symptoms, mortality, and hospitalization in patients receiving maintenance dialysis: a cohort study. Am J Kidney Dis 2019;74:158-66.

21 Tsai Y-C, Chiu Y-W, Hung C-C, et al. Association of symptoms of depression with progression of CKD. Am J Kidney Dis 2012;60:54-61.

22 Alston $\mathrm{H}$, Vickerstaff $\mathrm{V}$, Low J, et al. SP707VALIDATION of the distress thermometer in a UK renal population. Nephrol Dial Transplant 2015;30

$23 \mathrm{Ma} \mathrm{X}$, Zhang J, Zhong W, et al. The diagnostic role of a short screening tool--the distress thermometer: a meta-analysis. Support Care Cancer 2014:22:1741-55.

24 Alston $\mathrm{H}$. Psychosocial distress in older patients with advanced chronic kidney disease, 2018. Available: https://discovery.ucl.ac.uk/ id/eprint/10061352/1/Alston_thesis.pdf [Accessed 10 Jun 2020].

25 StataCorp. Stata statistical software: release 14. College Station, TX: StataCorp LP, 2015

26 Damery S, Brown C, Sein K, et al. The prevalence of mild-tomoderate distress in patients with end-stage renal disease: results from a patient survey using the emotion thermometers in four Hospital trusts in the West Midlands, UK. BMJ Open 2019:9:e027982.

27 Goh ZS, Griva K. Anxiety and depression in patients with end-stage renal disease: impact and management challenges - a narrative review. Int J Nephrol Renovasc Dis 2018;11:93-102.

28 National Renal Workforce Planning Group. The renal team a MultiProfessional renal workforce plan for adults and children with renal disease, 2002. Available: www.britishrenal.org [Accessed 2 Feb 2019].

29 Combes G, Damery S, Sein K, et al. Distress in patients with endstage renal disease: staff perceptions of barriers to the identification of mild-moderate distress and the provision of emotional support. PLoS One 2019;14:e0225269. 